\title{
Mono-dispersed Ag nanoparticles decorated graphitic carbon nitride: An excellent lubricating additive as PPESK composite film
}

\author{
Beibei CHEN ${ }^{1, *}$, Mengjie ZHANG ${ }^{1}$, Kan ZHANG ${ }^{1}$, Zhe DONG ${ }^{1}$, Jiaye LI $^{1}$, Gai ZHAO $^{2}$ \\ ${ }^{1}$ School of Materials and Science Engineering, Institute for Advanced Materials, Jiangsu University, Zhenjiang 212013, China \\ ${ }^{2}$ State Key Laboratory of Mechanics and Control of Mechanical Structures, Nanjing University of Aeronautics and Astronautics, \\ Nanjing 210016, China
}

Received: 24 September 2020 / Revised: 19 November 2020 / Accepted: 07 January 2021

(C) The author(s) 2021.

\begin{abstract}
Studies show that two dimensional (2D) nanomaterial and its hybrid have a great promise in tribology for the special laminar microstructure. However, the majority of performed investigations about $2 \mathrm{D}$ graphitic carbon nitride $\left(\mathrm{g}-\mathrm{C}_{3} \mathrm{~N}_{4}\right)$ nanosheets are most focused on energy storage, catalysis, adsorption, rarely tribology. In the present study, $\mathrm{g}-\mathrm{C}_{3} \mathrm{~N}_{4}$ supporting mono-dispersed $\mathrm{Ag}$ nanoparticle hybrid (g$\mathrm{C}_{3} \mathrm{~N}_{4} / \mathrm{Ag}$ ) is prepared, and its microstructure and chemical composition are determined. More specifically, the tribological performance as the lubricating additive of poly phthalazinone ether sulfone ketone (PPESK) composite is investigated using the ball-on-disc friction tester. Moreover, the corresponding enhancement mechanism is well proposed based on the experimental analysis and theoretical simulation. Obtained results show that $\mathrm{Ag}$ nanoparticles with a size of about $10-20 \mathrm{~nm}$ are homogeneously anchored on $\mathrm{g}-\mathrm{C}_{3} \mathrm{~N}_{4}$ nanosheets, favoring for good compatibility between $\mathrm{g}-\mathrm{C}_{3} \mathrm{~N}_{4} / \mathrm{Ag}$ and PPESK. It is found that when 0.3 ${ }_{\mathrm{wt}} \%$ of $\mathrm{g}-\mathrm{C}_{3} \mathrm{~N}_{4} / \mathrm{Ag}$ is added to PPESK, the friction coefficient and wear rate of PPESK decrease by $68.9 \%$ and $97.1 \%$, respectively. These reductions are mainly attributed to the synergistic self-lubricating effect of $\mathrm{Ag}$ nanoparticles and $\mathrm{g}-\mathrm{C}_{3} \mathrm{~N}_{4}$ nanosheet, the formation of transfer film, as well as the limited effect of g- $\mathrm{C}_{3} \mathrm{~N}_{4} / \mathrm{Ag}$ on the shear deformation of PPESK composite film. Furthermore, it is found that the proposed g- $\mathrm{C}_{3} \mathrm{~N}_{4} / \mathrm{Ag}$-PPESK composite still keeps reasonable friction-reducing and wear-resistant properties under heavy loads and high rotating speeds. The present study demonstrates that the proposed $\mathrm{g}-\mathrm{C}_{3} \mathrm{~N}_{4} / \mathrm{Ag}$ hybrid is an excellent lubricating additive for polymer composites.
\end{abstract}

Keywords: $\mathrm{g}-\mathrm{C}_{3} \mathrm{~N}_{4} / \mathrm{Ag}$ hybrid; poly phthalazine ether sulfone ketone (PPESK) composite film; friction; wear; theoretical simulation

\section{Introduction}

Studies show that friction and wear are two of the most important factors influencing the life of mechanical equipment. Moreover, these factors not only waste energy and resources but also accelerate the scraping process of equipment and reduce the maintenance period accordingly [1, 2]. Therefore, it is of significant importance to develop high-performance self-lubricating materials for being used in mechanical components to decrease the impact of friction and wear. In this regard, polymers and their composites have attracted many scholars in friction engineering. Since the emergence of polymers, superior characteristics such as lightweight, high specific strength, good friction and wear properties, excellent

* Corresponding author: Beibei CHEN, E-mail: chenbb@ujs.edu.cn 
corrosion resistance, and easy processing have been achieved so far [3-7]. For instance, poly phthalazine ether sulfone ketone (PPESK) is a good soluble polymer with rigid phthalazine structure and aromatic rings, and has excellent mechanical and thermal properties, and reasonable chemical stability [8, 9]. However, poor friction-reducing and antiwear properties of pure PPESK limit its tribological application in harsh operating conditions, so that it cannot satisfy the industrial demands [10].

Further investigations show that nanomaterials with two dimensional (2D) layered structures such as graphene/graphene oxide [11], $\mathrm{MoS}_{2}$ nanosheets [12], and hexagonal boron nitride (h-BN) nanosheets [13] have superior characteristics such as large specific surface, ease of shear, and good self-lubricating properties. In this regard, investigations have demonstrated that adding 2D layered nanomaterials greatly improves the tribological performance of polymers. Chen et al. [14] obtained a high-performance bismaleimide (BMI) composite with graphene/MoS2 nanosheets modified by hyperbranched polysiloxane. They found that the maximal impact and flexural strength of BMI modified by adding $0.8 \mathrm{wt} \%$ of graphene/ $\mathrm{MoS}_{2}$ are $22.4 \mathrm{~kJ} / \mathrm{m}^{2}$ and $187.8 \mathrm{MPa}$, respectively. Moreover, the lowest friction coefficient and wear rate were obtained for $0.4 \mathrm{wt} \%$ graphene/ MoS2-BMI composite. These improvements may originate from good dispersibility and self-lubrication of graphene/ $\mathrm{MoS}_{2}$ and its good compatibility with the BMI matrix. Yu et al. [15] showed that the tribological properties of the epoxy (EP) coating were greatly improved by silanecoupling agent 3-aminopropyltriethoxysine (APTES) functionalized cubic boron nitride (C-BN) and hexagonal boron nitride (h-BN) nanofillers. They found that as the content of fillers approached $0.5 \mathrm{wt} \%$, the corresponding EP composite coating had optimal friction and wear properties. More specifically, they demonstrated that the functionalized h-BN reinforced EP coating had excellent anti-friction capacity. This may be attributed to the h-BN with a hexagonal crystalline lamellar structure. Yuan et al. [16] prepared $\mathrm{MoS}_{2}$ nanosheets using high shear mixing technique and then filled them into poly(amic acid) (PAA) precursors to fabricate a $\mathrm{MoS}_{2} /$ polyimide $\left(\mathrm{MoS}_{2} / \mathrm{PI}\right)$ composite film. They showed that the mechanical strength and thermal resistance of PI increase remarkably. In particular, they found that applying $0.75 \mathrm{wt} \% \mathrm{MoS}_{2}$ nanosheets increased the tensile strength and Young's modulus of PI composite by $43 \%$ and $47 \%$, respectively [16]. Moreover, they showed that the tribological properties of PI composite film were improved by adding 2D fluorinated graphene nanosheets [17]. In addition, Chen et al. prepared 2D/2D hybrid of $\mathrm{h}-\mathrm{BN} / \mathrm{MoS}_{2}$ and then incorporated it into the epoxy matrix to realize the good tribological properties of epoxy composite coating [18]. It is worth noting that graphitic carbon nitride $\left(\mathrm{g}-\mathrm{C}_{3} \mathrm{~N}_{4}\right)$ is a typical graphite-like layered structure with weak van der Waals interactions between layers $[19,20]$, and might have excellent self-lubricating properties similar to graphite or MoS2. Wang et al. modified $\mathrm{g}-\mathrm{C}_{3} \mathrm{~N}_{4}$ through the alkali treatment and thermal etching methods, and improved the wear resistance of PEEK accordingly. This improvement originates from its dense stacking structure [21]. Zhu et al. increased the thermal decomposition temperature of PI by adding g- $\mathrm{C}_{3} \mathrm{~N}_{4}$. They found that as $10 \mathrm{wt} \%$ of $\mathrm{g}-\mathrm{C}_{3} \mathrm{~N}_{4}$ is added to the PI, optimized friction-reducing and wear-resistant properties of PI can be obtained. This is mainly because $\mathrm{g}-\mathrm{C}_{3} \mathrm{~N}_{4}$ with good self-lubricating property facilitates the formation of continuous transfer film on the counterpart surface during sliding contact [22].

On the other hand, metal and metal oxide nanoparticles have been widely applied in tribology. This mainly originates from desirable characteristics of these nanoparticles such as tiny size, simplicity of production, high ductility, low shear stress, and good reinforcing and lubricating effect. Choi et al. found that the wear resistance and load-carrying capacity of the base oil can be improved by the incorporation of Ni nanoparticles [23]. Tarasov et al. reported that $\mathrm{Cu}$ nanoparticles have excellent lubricating properties so that these nanoparticles can act as nano-bearing and effectively form tribofilms on the sliding surface [24]. Recently, it has been confirmed that metal nanoparticles and 2D nanosheets can play a synergistic enhancing effect on the tribological properties of materials. In this regard, their hybrids have been prepared through 
various methods. For example, Jia et al. [25] fabricated $\mathrm{Cu}$ nanoparticles@MoS${ }_{2}$ nanosheets and obtained excellent tribological properties. They proved that $\mathrm{MoS}_{2}$ nanosheets provided a substrate for $\mathrm{Cu}$ nanoparticles to avoid aggregation so that the provided hybrid material promoted the formation of the stable transfer film. Moreover, $\mathrm{Cu} /$ reduced graphene oxide hybrid was prepared through the in-situ reduction method, and excellent tribological properties were achieved by the hybrid material [26, 27]. Silver (Ag) nanoparticle is a typical soft metal and has a low melting point and good lubricating properties. Investigations show that Ag nanoparticles and its hybrids with other materials have great application potential in the field of tribology [28, 29]. It is expected that the hybrid of Ag nanoparticles and 2D g- $\mathrm{C}_{3} \mathrm{~N}_{4}\left(\mathrm{~g}-\mathrm{C}_{3} \mathrm{~N}_{4} / \mathrm{Ag}\right)$ might be an excellent lubricating additive for polymer composites. However, no investigation has been conducted so far to study the enhancement effect of $\mathrm{g}-\mathrm{C}_{3} \mathrm{~N}_{4} / \mathrm{Ag}$ hybrid on the tribological behaviors of polymer composites.

In the present study, it is intended to fabricate a hybrid of mono-dispersed $\mathrm{Ag}$ nanoparticles and $2 \mathrm{D} \mathrm{g}-\mathrm{C}_{3} \mathrm{~N}_{4}$ nanosheets through the method of facile in-situ reduction, while the corresponding $g-\mathrm{C}_{3} \mathrm{~N}_{4} / \mathrm{Ag}$ hybrid reinforced PPESK nanocomposite films are fabricated through the tape-casting method. The microstructure and phase composition of g $\mathrm{C}_{3} \mathrm{~N}_{4} / \mathrm{Ag}$ will be determined and the thermal stability, friction, and wear performance of PPESK composite films will be investigated in detail. Moreover, the enhancement mechanism of $\mathrm{g}-\mathrm{C}_{3} \mathrm{~N}_{4} / \mathrm{Ag}$ will be discussed based on theoretical simulation using Materials Studio software and worn surface analysis.

\section{Experimental}

\subsection{Materials}

In this experiment, urea (AR), polyvinylpyrrolidone (PVP, K30, GR), N, N-Dimethylacetamide (DMA, AR), and silver nitrate (AgNO3, 99.8\%) are provided from Sinopharm Chemical Reagent Co., Ltd. Moreover, ammonia water $\left(\mathrm{NH}_{3} \cdot \mathrm{H}_{2} \mathrm{O}, 25 \%-28 \%\right.$, $\left.\mathrm{AR}\right)$ is supplied by Yangzhou Shanghai Chemical Reagent Co., Ltd. PPESK is obtained from Dalian University of Techno$\operatorname{logy}$ (China).

\subsection{Preparation of g- $\mathrm{C}_{3} \mathrm{~N}_{4} / \mathrm{Ag}$ hybrid}

g- $\mathrm{C}_{3} \mathrm{~N}_{4}$ nanosheets are prepared via one-step calcinations. To this end, urea was initially placed in a trioxo$\mathrm{Al}_{2} \mathrm{O}_{3}$ porcelain boat under a $\mathrm{N}_{2}$ atmosphere and heated with a temperature rising rate of $1.9^{\circ} \mathrm{C} / \mathrm{min}$ until the temperature approached $350{ }^{\circ} \mathrm{C}$, where the urea was maintained at this temperature for $2 \mathrm{~h}$. Then it was heated to $550{ }^{\circ} \mathrm{C}$ for $2 \mathrm{~h}$ with an increasing rate of $3.3^{\circ} \mathrm{C} / \mathrm{min}$. Finally, the $\mathrm{g}-\mathrm{C}_{3} \mathrm{~N}_{4}$ powder was obtained after cooling naturally. Then $0.1 \mathrm{~g}$ of $\mathrm{g}-\mathrm{C}_{3} \mathrm{~N}_{4}$ was weighed and dissolved into $100 \mathrm{~mL}$ deionized water by means of an ultrasonic and magnetic stirrer. $0.3 \mathrm{~g}$ $\mathrm{AgNO}_{3}$ was dissolved into $50 \mathrm{~mL}$ deionized water and then appropriate $\mathrm{NH}_{3} \cdot \mathrm{H}_{2} \mathrm{O}$ was dropped into a silver nitrate solution until the mixed solution became transparent. Then, the two solutions of $\mathrm{g}-\mathrm{C}_{3} \mathrm{~N}_{4}$ and $\mathrm{AgNO}_{3}$ were mixed together. Subsequently, $\mathrm{Ag}^{+}$ was adsorbed on the surface of $\mathrm{g}-\mathrm{C}_{3} \mathrm{~N}_{4}$ nanosheets. Moreover, $0.5 \mathrm{~g}$ PVP as the dispersant and stabilizer was added into the mixed solution. The solution was kept for $8 \mathrm{~h}$ at $80^{\circ} \mathrm{C}$ in oil bath, while it was stirred magnetically during the whole process. The reduction of $\mathrm{Ag}^{+}$was continued for 40 minutes through UV irradiation. Finally, the product was washed thoroughly with deionized water and absolute ethyl alcohol, and then centrifuged and freeze-dried, and the $\mathrm{g}-\mathrm{C}_{3} \mathrm{~N}_{4} / \mathrm{Ag}$ hybrid was obtained. In order to compare the performance of different materials, $\mathrm{Ag}$ nanoparticles were prepared with a similar method.

\subsection{Preparation of PPESK composite film}

Appropriate PPESK powder and g- $\mathrm{C}_{3} \mathrm{~N}_{4} / \mathrm{Ag}$ hybrid were dissolved and dispersed uniformly through an ultrasonic stirrer in a $10 \mathrm{~mL}$ DMA. Then, the mixed solution was poured into a special mold with dimensions of $170 \mathrm{~mm} \times 50 \mathrm{~mm} \times 5 \mathrm{~mm}$, and then put into a vacuum drying oven to remove the solvent. The curing procedure of the PPESK composite film consists of keeping the composite at $60^{\circ} \mathrm{C}$ for $8 \mathrm{~h}$ and then followed by $4 \mathrm{~h}$ at $80{ }^{\circ} \mathrm{C}$. Four specimens with different contents of $\mathrm{g}-\mathrm{C} 3 \mathrm{~N} 4 / \mathrm{Ag}$ hybrid, including $0.05 \mathrm{wt} \%, 0.1 \mathrm{wt} \%, 0.3 \mathrm{wt} \%$, and $0.5 \mathrm{wt} \%$ were prepared. Moreover, pure PPESK and g- $\mathrm{C}_{3} \mathrm{~N}_{4}$-PPESK composite films were prepared for the comparison. The thickness of as-prepared PPESK and its composite film was about $0.2 \mathrm{~mm}$. 


\subsection{Characterization}

The crystal structure of $\mathrm{g}-\mathrm{C}_{3} \mathrm{~N}_{4} / \mathrm{Ag}$ was characterized by an advanced X-ray diffractometer (XRD, Cu K $\alpha 1$, Bruker, Germany). The infrared spectrums of g- $\mathrm{C}_{3} \mathrm{~N}_{4}$ and $\mathrm{g}-\mathrm{C}_{3} \mathrm{~N}_{4} / \mathrm{Ag}$ were determined using the Fourier transform infrared spectrometer (Nicolet iS50FTIR, FIIR, U.S.). Besides, a transmission electron microscope (TEM, JEM-2100, JEOL) and field emission scanning electron microscope (FESEM, JSM-7800F, JEOL) were used to characterize the microstructure of $\mathrm{Ag}$, g- $\mathrm{C}_{3} \mathrm{~N}_{4}$, and $\mathrm{g}-\mathrm{C}_{3} \mathrm{~N}_{4} / \mathrm{Ag}$ hybrid. And the working distance was $10 \mathrm{~mm}$ and accelerating voltage was $15.0 \mathrm{kV}$ in FESEM characterization. And before FESEM observation, the specimens were sputtered with gold to increase the electrical conductivity.

Thermal stability of PPESK and its composite films were investigated via TGA tests using a comprehensive thermal analyzer (Nai Chi STA 449 F3, Gerrmany) under $\mathrm{N}_{2}$ atmosphere, while the operating temperature varied from room temperature to $800^{\circ} \mathrm{C}$ with a heating rate of $10{ }^{\circ} \mathrm{C} / \mathrm{min}$. Besides, tribological tests were carried out on a ball-on-disk friction experiment tester (MPX-3C). Figure 1 shows the friction schematic diagram. The friction pair was $440 \mathrm{C}$ stainless steel ball with a diameter of $8 \mathrm{~mm}$. The experimental procedure of dry sliding was measured for $20 \mathrm{~min}$ with applied loads of $4 \mathrm{~N}, 6 \mathrm{~N}, 8 \mathrm{~N}$, and $10 \mathrm{~N}$, and sliding speeds of $100 \mathrm{rpm}, 150 \mathrm{rpm}, 200 \mathrm{rpm}$, and $250 \mathrm{rpm}$. Finally, the worn surface images and element analysis of PPESK composite films were observed by SEM and EDS. The wear rate of the sample can be calculated from the following expression:

$$
K=\frac{V}{L \times d}
$$

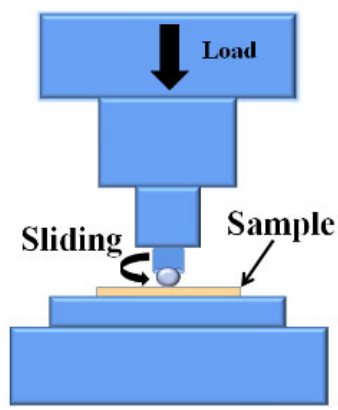

Fig. 1 Schematic diagram of friction and wear test. where $V\left(\mathrm{~mm}^{3}\right), L(\mathrm{~N})$, and $d(\mathrm{~m})$ denote the wear volume, applied load, and sliding distance, respectively. Meanwhile, the wear volume $(V)$ can be calculated from the following expression:

$$
V=\Pi\left[h \times R^{2}-\frac{R^{3}}{3}+\frac{(R-h)^{3}}{3}\right]
$$

where $R(\mathrm{~mm})$ is the ball radius, and $S(\mathrm{~mm})$ and $h$ $(\mathrm{mm})$ denote the width and depth of wear track, respectively. The wear scar width was measured by an optical microscope (Zeiss Metallographic Microscope, Observer. $\mathrm{Z1m}$ ). For each sample, five friction and wear tests were carried out, and the average values were reported.

In order to accurately evaluate the enhancing effect of g- $\mathrm{C}_{3} \mathrm{~N}_{4} / \mathrm{Ag}$ hybrid on the tribological properties of PPESK, Materials Studio software was employed to simulate the friction and wear processes. Moreover, the condensed-phase optimized potentials for atomistic simulation studies (COMPASS) force field was used [30]. In the present study, the counterpart is made of $440 \mathrm{C}$ stainless steel, which is mainly composed of Fe element. Therefore, it was substituted by $\mathrm{Fe}$ atomic layers in the friction model to facilitate the calculation. Details of the theoretical simulation are provided in the Electronic Supplementary Material (ESM).

\section{Results and discussion}

\subsection{Characterization of the $\mathrm{g}-\mathrm{C}_{3} \mathrm{~N}_{4} / \mathrm{Ag}$ hybrid}

Figure 2 presents the characterized microstructure and surface morphology of $\mathrm{g}-\mathrm{C}_{3} \mathrm{~N}_{4}, \mathrm{Ag}$, and g- $\mathrm{C}_{3} \mathrm{~N}_{4} /$ Ag hybrid through FESEM and TEM. It is observed that the prepared $\mathrm{g}-\mathrm{C}_{3} \mathrm{~N}_{4}$ is a $2 \mathrm{D}$ layer microstructure similar to graphene, and has clear features of transparency, wrinkles, and lightness in Figs. 2(a) and 2(b). Figures 2(c) and 2(d) illustrate that Ag nanoparticles undergo serious aggregation so that "grape cluster" shapes are formed. It is found that the size distribution of $\mathrm{Ag}$ nanoparticles is uneven. However, Figs. 2(e) and 2(f) show that the spherical Ag nanoparticles are homogeneously decorated on the surface of $\mathrm{g}-\mathrm{C}_{3} \mathrm{~N}_{4}$ nanosheets. Moreover, they are mono-dispersed with a size of about $10-20 \mathrm{~nm}$. This is because $\mathrm{g}-\mathrm{C}_{3} \mathrm{~N}_{4}$ nanosheets can be an appropriate 

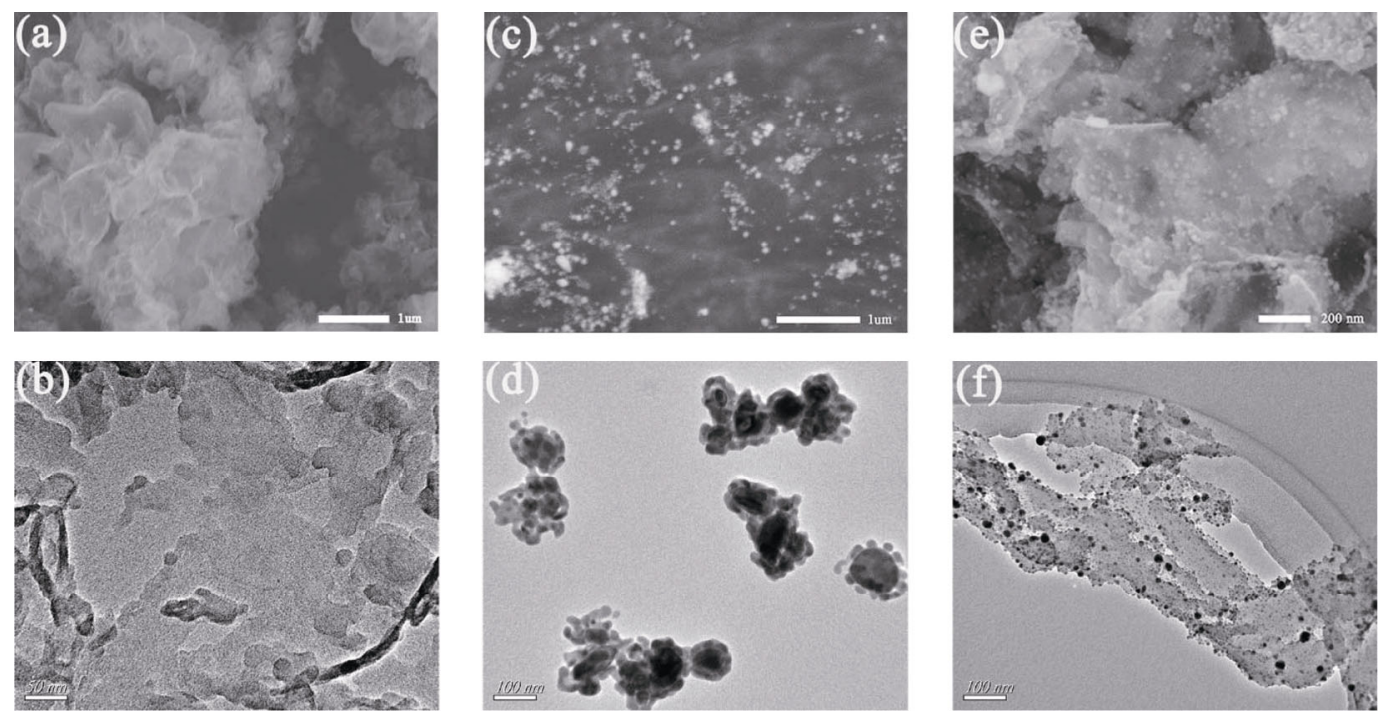

Fig. 2 FESEM and TEM of microstructure of $g-C_{3} \mathrm{~N}_{4}$ nanosheets (a, b), Ag nanoparticles (c, d), and g- $\mathrm{C}_{3} \mathrm{~N}_{4} / \mathrm{Ag}$ hybrid (e, f).

substrate for the adsorption of $\mathrm{Ag}^{+}$, and the functional groups (i.e., $-\mathrm{OH}$ and $\mathrm{NH}_{2}$ ) on $\mathrm{g}-\mathrm{C}_{3} \mathrm{~N}_{4}$ enhance the interaction between $\mathrm{Ag}^{+}$and $\mathrm{g}_{-} \mathrm{C}_{3} \mathrm{~N}_{4}$. Meanwhile, the PVP is a good dispersant and stabilizer substance during the reduction reaction process and prevents the aggregation of Ag nanoparticles [31, 32].

In this section, it is intended to characterize the chemical composition and phase structure of the g- $\mathrm{C}_{3} \mathrm{~N}_{4} / \mathrm{Ag}$ hybrid. Figure 3(a) illustrates the FTIR spectrums of $g-C_{3} N_{4}$ and g- $C_{3} N_{4} / A g$. For pure g- $C_{3} N_{4}$ nanosheets, it is found that there is a wide peak in the range of 3,000-3,500 $\mathrm{cm}^{-1}$, which originates from the vibration mode of secondary amines $(=\mathrm{N}-\mathrm{H})$, primary amines $\left(-\mathrm{NH}_{2}\right)$, and stretching vibration of $-\mathrm{OH}$. Moreover, the sharp characteristic band at $808 \mathrm{~cm}^{-1}$ corresponds to the vibration of representative $1,3,5$ substituted benzene ring structure. The absorption bands in the range of $1,700-1,200 \mathrm{~cm}^{-1}$ are assigned to the stretching vibration of the conjugated $\mathrm{CN}$ rings. More specifically, the absorption peaks at the position of $1,317 \mathrm{~cm}^{-1}, 1,571 \mathrm{~cm}^{-1}$, and 1,636 $\mathrm{cm}^{-1}$ are attributed to the stretching vibration of $\mathrm{C}-\mathrm{N}, \mathrm{C}=\mathrm{C}$, and $\mathrm{C}=\mathrm{N}$ structure, respectively $[33,34]$. It is found that all absorbance bands of $\mathrm{g}-\mathrm{C}_{3} \mathrm{~N}_{4} / \mathrm{Ag}$ hybrid within the range of $500-4,000 \mathrm{~cm}^{-1}$ are similar to the typical characteristic bands of g- $\mathrm{C}_{3} \mathrm{~N}_{4}$, except for a decreased intensity of some absorption bands caused by the decoration of Ag nanoparticles on g- $\mathrm{C}_{3} \mathrm{~N}_{4}$ nanosheets. This indicates that no obvious structural change of $\mathrm{g}-\mathrm{C}_{3} \mathrm{~N}_{4}$ occurs during the preparation process. Figure 3(b) further exhibits the XRD patterns of $\mathrm{g}-\mathrm{C}_{3} \mathrm{~N}_{4}, \mathrm{Ag}$ nanoparticle, and g- $\mathrm{C}_{3} \mathrm{~N}_{4} / \mathrm{Ag}$ hybrid. It is found that $\mathrm{g}-\mathrm{C}_{3} \mathrm{~N}_{4}$ nanosheets have two characteristic diffraction peaks of (100) and (002) crystal planes at $2 \theta$ value of $12.7^{\circ}$ and $27.5^{\circ}$, which are closely related to the interplanar structural packing and interlayer stacking structure [35, 36]. For Ag nanoparticles, the characteristic diffraction peaks at positions of $38^{\circ}, 44.3^{\circ}, 64.3^{\circ}, 77.3^{\circ}$, and $81.5^{\circ}$ are matched with (111), (200), (220), (311), and (222) planes of Ag face-centered cubic structure, respectively [37, 38]. For the XRD pattern of the g- $\mathrm{C}_{3} \mathrm{~N}_{4} / \mathrm{Ag}$ hybrid, not only there are Ag characteristic diffraction peaks but also g- $\mathrm{C}_{3} \mathrm{~N}_{4}$ diffraction peaks. Nevertheless, the intensity of characteristic diffraction peaks of $\mathrm{g}-\mathrm{C}_{3} \mathrm{~N}_{4}$ is much weaker, which originates from a large amount of $\mathrm{Ag}$ nanoparticles being decorated on g- $\mathrm{C}_{3} \mathrm{~N}_{4}$ nanosheets. Figure 3(c) illustrates the EDS of $g-C_{3} N_{4} / A g$, while the presence of $C, N$, and $A g$ element reveals that the prepared $g-\mathrm{C}_{3} \mathrm{~N}_{4} / \mathrm{Ag}$ has high purity. The foregoing discussions demonstrate that the $\mathrm{g}-\mathrm{C}_{3} \mathrm{~N}_{4} / \mathrm{Ag}$ hybrid has been successfully fabricated.

\subsection{Thermal properties of PPESK composite film with $\mathrm{g}-\mathrm{C}_{3} \mathrm{~N}_{4} / \mathrm{Ag}$}

The effect of the $\mathrm{g}-\mathrm{C}_{3} \mathrm{~N}_{4} / \mathrm{Ag}$ hybrid on the thermal stability of PPESK is investigated by comparing PPESK and $g-\mathrm{C}_{3} \mathrm{~N}_{4}$-PPESK composite. Figure 4 shows TG curves of these composites when the content of 

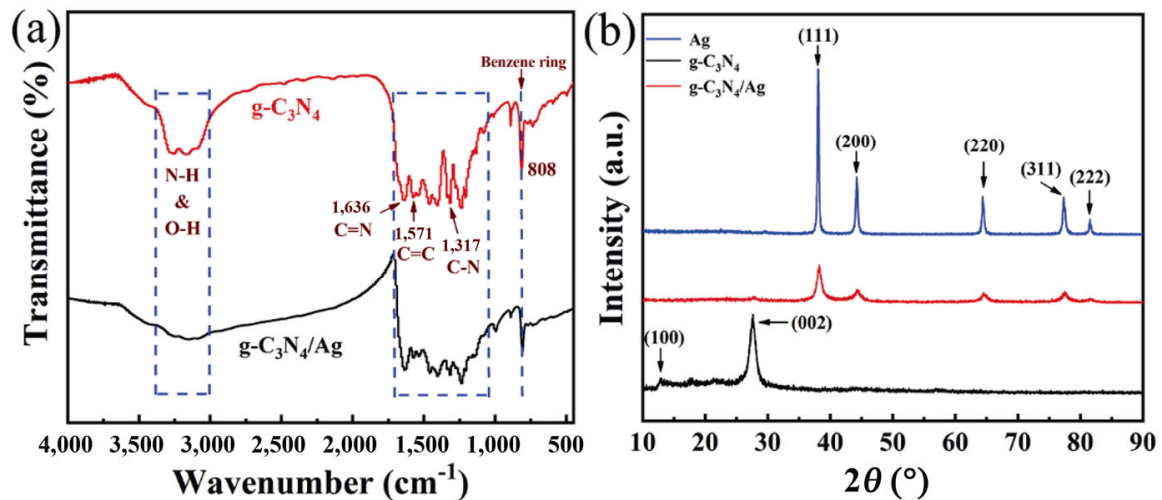

(c)

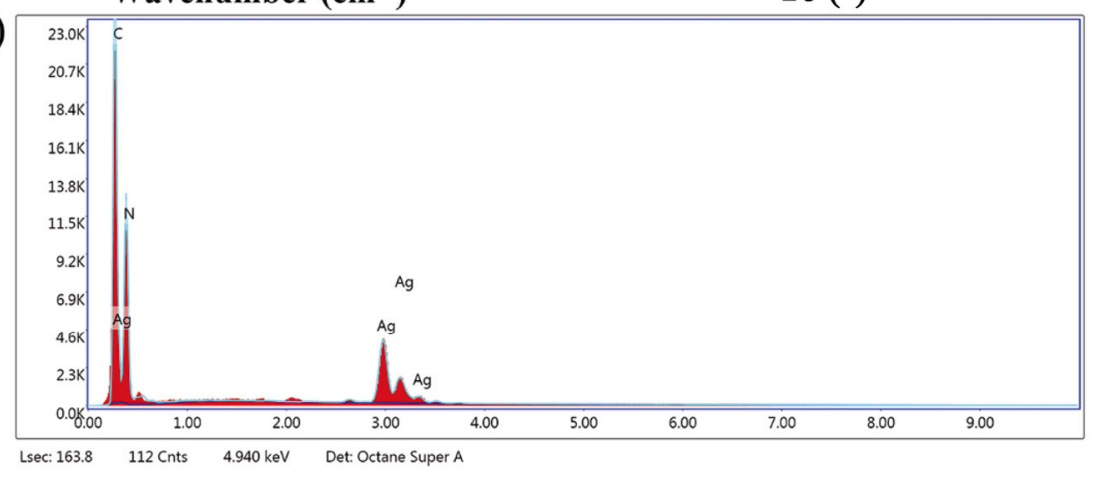

Fig. 3 FTIR spectrums of $g-\mathrm{C}_{3} \mathrm{~N}_{4}$ and g- $\mathrm{C}_{3} \mathrm{~N}_{4} / \mathrm{Ag}$ (a); XRD patterns of $\mathrm{g}-\mathrm{C}_{3} \mathrm{~N}_{4}, \mathrm{Ag}$ nanoparticles, and $\mathrm{g}-\mathrm{C}_{3} \mathrm{~N}_{4} / \mathrm{Ag}$ (b); EDS of g- $\mathrm{C}_{3} \mathrm{~N}_{4} / \mathrm{Ag}$ hybrid (c).

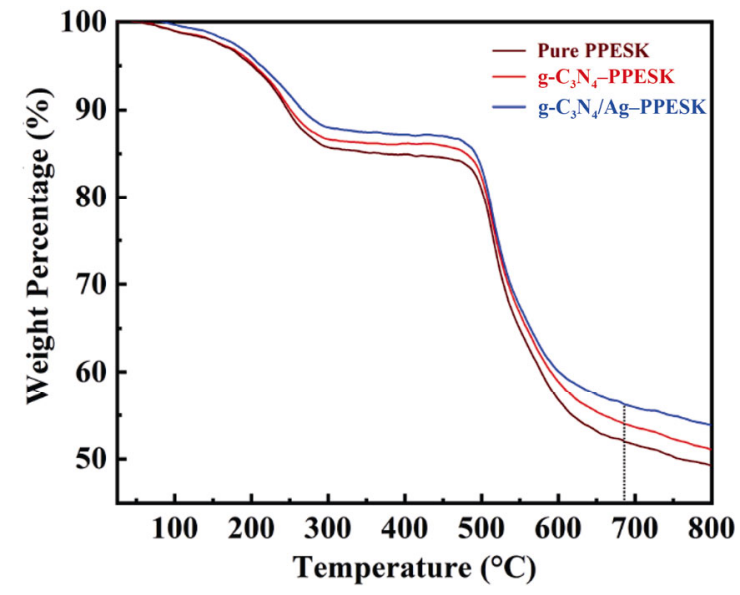

Fig. 4 TG curves of PPESK and its composite films.

g- $\mathrm{C}_{3} \mathrm{~N}_{4}$ and $\mathrm{g}-\mathrm{C}_{3} \mathrm{~N}_{4} / \mathrm{Ag}$ is $0.3 \mathrm{wt} \%$. It indicates that PPESK and its composite films suffer from a similar variation tendency in the process of thermal decomposition, consisting of several stages. The first stage ranging from room temperature to $300{ }^{\circ} \mathrm{C}$ mainly refers to the evaporation of residual solvent of DMA and some small released gases, in which the weight loss is about $16 \%$. In this stage, PPESK suffers from the transition of the glassy state to the rubber state. Besides, in the stage from 450 to $680{ }^{\circ} \mathrm{C}$, remarkable thermal degradation of occurs, resulting in an obvious weight loss. Accordingly, scissions of molecular chains and the coalescent of the remained chemical functional groups of the PPESK matrix occur [39]. In particular, as the temperature approaches $680{ }^{\circ} \mathrm{C}$, the residual weight fraction of PPESK, g- $\mathrm{C}_{3} \mathrm{~N}_{4}-\mathrm{PPESK}$, g- $\mathrm{C}_{3} \mathrm{~N}_{4} / \mathrm{Ag}$-PPESK approach $50.19 \%, 54.16 \%$, and $56.48 \%$, respectively. This indicates that adding fillers improves the thermal resistance of PPESK. It is found that such improvement is especially more pronounced for the proposed $\mathrm{g}-\mathrm{C}_{3} \mathrm{~N}_{4} / \mathrm{Ag}$ hybrid. This is because $g-C_{3} N_{4}$ and $g-C_{3} N_{4} / A g$ have active functional groups (e.g., $-\mathrm{NH},-\mathrm{OH},-\mathrm{NH}_{2}, \mathrm{C}=\mathrm{C}$ ), which enhance the interfacial chemical bonding interaction between g- $\mathrm{C}_{3} \mathrm{~N}_{4}$ and PPESK matrix via van der Waals and $\pi-\pi$ forces, thereby preventing the movement of PPESK molecular chain and inhibiting the generation of gases. Consequently, PPESK composite film with high thermal properties is obtained. Moreover, monodispersed Ag nanoparticles decorating on g- $\mathrm{C}_{3} \mathrm{~N}_{4}$ nanosheets can promote heat transmission. This feature originates from the intrinsic good thermal conductivity of silver. Meanwhile, the agglomeration of $\mathrm{g}-\mathrm{C}_{3} \mathrm{~N}_{4}$ nanosheets can be inhibited because of the presence 
of Ag nanoparticles. It is worth noting that this feature is desirable for improving the interfacial interaction between $\mathrm{g}-\mathrm{C}_{3} \mathrm{~N}_{4} / \mathrm{Ag}$ and PPESK. It is concluded that the PPESK composite film containing $\mathrm{g}-\mathrm{C}_{3} \mathrm{~N}_{4} / \mathrm{Ag}$ hybrid exhibits high thermal property, resulting in excellent tribological properties of the composite film.

\subsection{Tribological properties of PPESK composite films with g-C $3 \mathrm{~N}_{4} / \mathrm{Ag}$ hybrid}

Figure 5(a) shows the friction and wear properties of various contents of $\mathrm{g}-\mathrm{C}_{3} \mathrm{~N}_{4} / \mathrm{Ag}$ hybrid reinforced PPESK composite films in a dry sliding against a $440 \mathrm{C}$ stainless ball at the rotating speed of $100 \mathrm{rpm}$ and a load of $4 \mathrm{~N}$. It is observed that the friction coefficient of PPESK composite films decreases as the g- $\mathrm{C}_{3} \mathrm{~N}_{4} / \mathrm{Ag}$ hybrid increases. This reduction continues until it reaches the lowest value, where the content of $\mathrm{g}-\mathrm{C}_{3} \mathrm{~N}_{4} / \mathrm{Ag}$ reaches $0.3 \mathrm{wt} \%$. Subsequently, when the content of $\mathrm{g}-\mathrm{C}_{3} \mathrm{~N}_{4} / \mathrm{Ag}$ hybrid exceeds $0.3 \mathrm{wt} \%$, the friction coefficient of composite film increases slightly. It is concluded that the PPESK composite film with $0.3 \mathrm{wt} \%$ of $\mathrm{g}-\mathrm{C}_{3} \mathrm{~N}_{4} / \mathrm{Ag}$ hybrid has the best friction-reducing performance. This can be physically interpreted as the following: when the content of g- $\mathrm{C}_{3} \mathrm{~N}_{4} / \mathrm{Ag}$ hybrid is less than $0.3 \mathrm{wt} \%$, it cannot fill the matrix uniformly so that it cannot play good enhancing effect. On the other hand, less additives are prone to cause defects inside the material. However, when the content of $\mathrm{g}-\mathrm{C}_{3} \mathrm{~N}_{4} / \mathrm{Ag}$ exceeds $0.3 \mathrm{wt} \%$, the poor tribological performance of the corresponding composite film may be caused by the accumulation of $\mathrm{g}-\mathrm{C}_{3} \mathrm{~N}_{4} / \mathrm{Ag}$ hybrid. Figure 5 (b) presents the curves of the friction coefficient of PPESK and its composite films varying with the sliding time. It is found that at the initial stage of sliding process, the friction coefficient of pure PPESK increases sharply and then gradually reaches a stable level. Moreover, obvious fluctuation appears during the whole friction and wear process, indicating the PPESK with a poor lubricating property. However, with the incorporation of $g-\mathrm{C}_{3} \mathrm{~N}_{4} / \mathrm{Ag}$ hybrid, all PPESK composite films show much lower and more stable friction coefficient. This is especially more pronounced for the PPESK composite film with 0.3 wt $\%$ of g-C3N4/Ag. Moreover, Fig. 5(a) indicates that the wear rate of PPESK composite films exhibit similar variation of the friction coefficient. It is observed that as the content of $\mathrm{g}-\mathrm{C}_{3} \mathrm{~N}_{4} / \mathrm{Ag}$ hybrid reaches $0.3 \mathrm{wt} \%$, the corresponding PPESK composite film has the best friction-reducing and anti-wear properties.

In order to further investigate the influence of $\mathrm{g}$ $\mathrm{C}_{3} \mathrm{~N}_{4} / \mathrm{Ag}$ on the friction and wear properties of PPESK, the friction coefficient and wear rate of PPESK, g- $\mathrm{C}_{3} \mathrm{~N}_{4}-$ PPESK, and $g-\mathrm{C}_{3} \mathrm{~N}_{4} / \mathrm{Ag}-\mathrm{PPESK}$ are comparatively tested. Figure 6(a) presents obtained results in this regard. It is found that filling $\mathrm{g}-\mathrm{C}_{3} \mathrm{~N}_{4}$ improves the tribological properties of PPESK. As a result, an excellent self-lubricating property is achieved because of its interlayer bonding through van der Waals forces [40]. On the other hand, the friction coefficient and wear rate of $\mathrm{g}-\mathrm{C}_{3} \mathrm{~N}_{4} / \mathrm{Ag}-\mathrm{PPESK}$ are not only much lower than those of PPESK, but also are lower than those of $\mathrm{g}-\mathrm{C}_{3} \mathrm{~N}_{4}$ reinforced PPESK composite film. It is found that the friction coefficient and wear
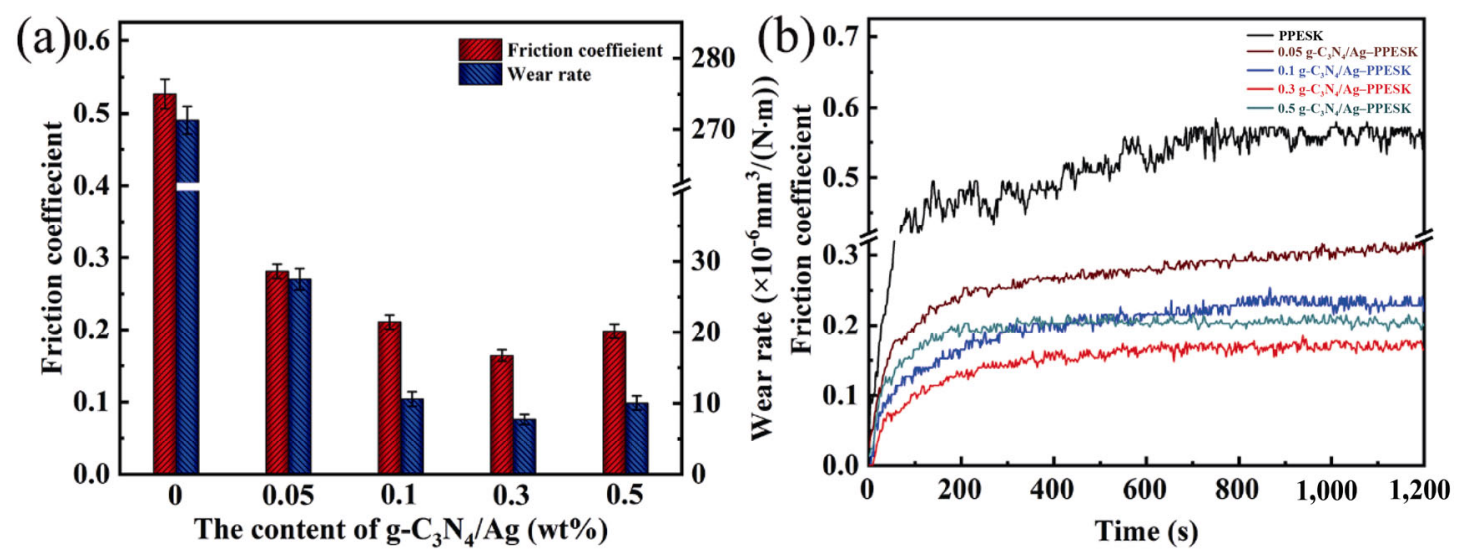

Fig. 5 Friction coefficient and wear rate of PPESK composite film with various content of g- $\mathrm{C}_{3} \mathrm{~N}_{4} / \mathrm{Ag}$ hybrid sliding against 440C stainless ball under $4 \mathrm{~N}, 100 \mathrm{rpm}$ (a); variation of friction coefficient of PPESK composite films with sliding time (b). 

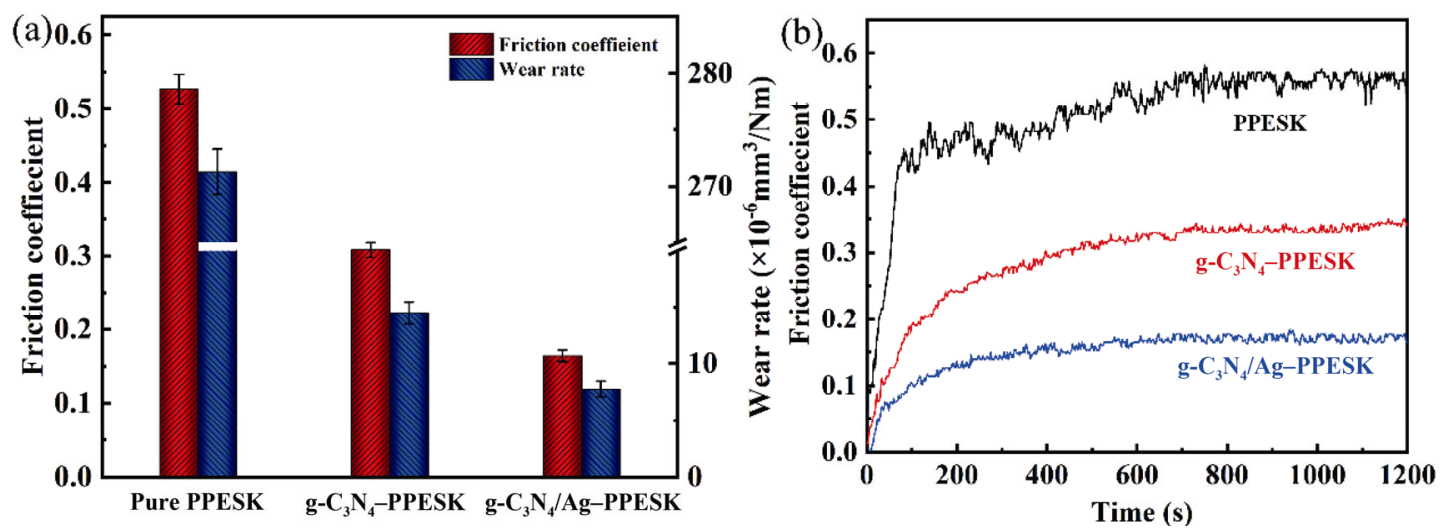

Fig. 6 (a) Tribological properties of PPESK, g- $\mathrm{C}_{3} \mathrm{~N}_{4}-$ PPESK, and g- $\mathrm{C}_{3} \mathrm{~N}_{4} / \mathrm{Ag}-\mathrm{PPESK}$ sliding against $440 \mathrm{C}$ stainless ball under $4 \mathrm{~N}, 100 \mathrm{rpm}$; (b) variation of friction coefficient of PPESK and its composite films with sliding time.

rate are 0.164 and $7.7 \times 10^{-6}$, respectively. These values are reduced by $68.9 \%$ and $97.1 \%$ lower than those of pure PPESK, respectively. This is because $\mathrm{g}-\mathrm{C}_{3} \mathrm{~N}_{4}$ and $\mathrm{Ag}$ nanoparticles are additives with intrinsically good lubricating features [41, 42]. Consequently, these additives have a good friction-reducing effect on the PPESK matrix. More importantly, g- $\mathrm{C}_{3} \mathrm{~N}_{4}$ nanosheets work as a platform for Ag nanoparticles, making Ag nanoparticles mono-dispersion. Meanwhile, the decoration of $\mathrm{Ag}$ nanoparticles can avoid the aggregation of $\mathrm{g}-\mathrm{C}_{3} \mathrm{~N}_{4}$ nanosheets by decreasing the interaction between nanosheets, which increases the synergistic lubricating effect between g- $\mathrm{C}_{3} \mathrm{~N}_{4}$ and Ag nanoparticles. Based on the FTIR analysis of $\mathrm{g}^{-} \mathrm{C}_{3} \mathrm{~N}_{4} / \mathrm{Ag}$, it is inferred that there are many functional groups on the $\mathrm{g}-\mathrm{C}_{3} \mathrm{~N}_{4} / \mathrm{Ag}$ hybrid, which can improve the interfacial physical and chemical interaction between $\mathrm{g}_{-} \mathrm{C}_{3} \mathrm{~N}_{4} / \mathrm{Ag}$ and PPESK, so that further decrease the shear deformation during the friction and wear process. This can be further determined from the theoretical simulation friction and wear results of PPESK, $\mathrm{g}-\mathrm{C}_{3} \mathrm{~N}_{4}-\mathrm{PPESK}$, and $\mathrm{g}-\mathrm{C}_{3} \mathrm{~N}_{4}$ / Ag-PPESK composites shown in Fig. 7. It is observed that PPESK, g- $\mathrm{C}_{3} \mathrm{~N}_{4}-\mathrm{PPESK}$, and $\mathrm{g}-\mathrm{C}_{3} \mathrm{~N}_{4} / \mathrm{Ag}-\mathrm{PPESK}$ have different shear deformation during the simulating sliding time of 200 ps. More specially, the shear deformation of PPESK, g- $\mathrm{C}_{3} \mathrm{~N}_{4}-\mathrm{PPESK}$, and $\mathrm{g}-\mathrm{C}_{3} \mathrm{~N}_{4} /$ Ag-PPESK after the friction and wear are $32.78 \AA$, $20.98 \AA$, and $15.37 \AA$, respectively. It indicates that among studied cases, $\mathrm{g}-\mathrm{C}_{3} \mathrm{~N}_{4} / \mathrm{Ag}-\mathrm{PPESK}$ has the highest shear strength and the best tribological properties. The interaction potential energy between PPESK composite films and Fe atomic layers during the friction and wear processes can be calculated by the following equation.

$$
E_{\text {inter }}=E_{\text {total }}-E_{\text {polymer }}-E_{\mathrm{Fe}}
$$

where $E_{\text {total }}, E_{\text {polymer }}$, and $E_{\mathrm{Fe}}$ denote the energies of the whole friction system, PPESK or PPESK composite film, and Fe atomic layers, respectively. It is observed that the interaction potential energy of all friction systems fluctuates with the sliding time due to different interaction sites. Besides, pure PPESK has the highest average energy of 2,559.8 kcal/mol

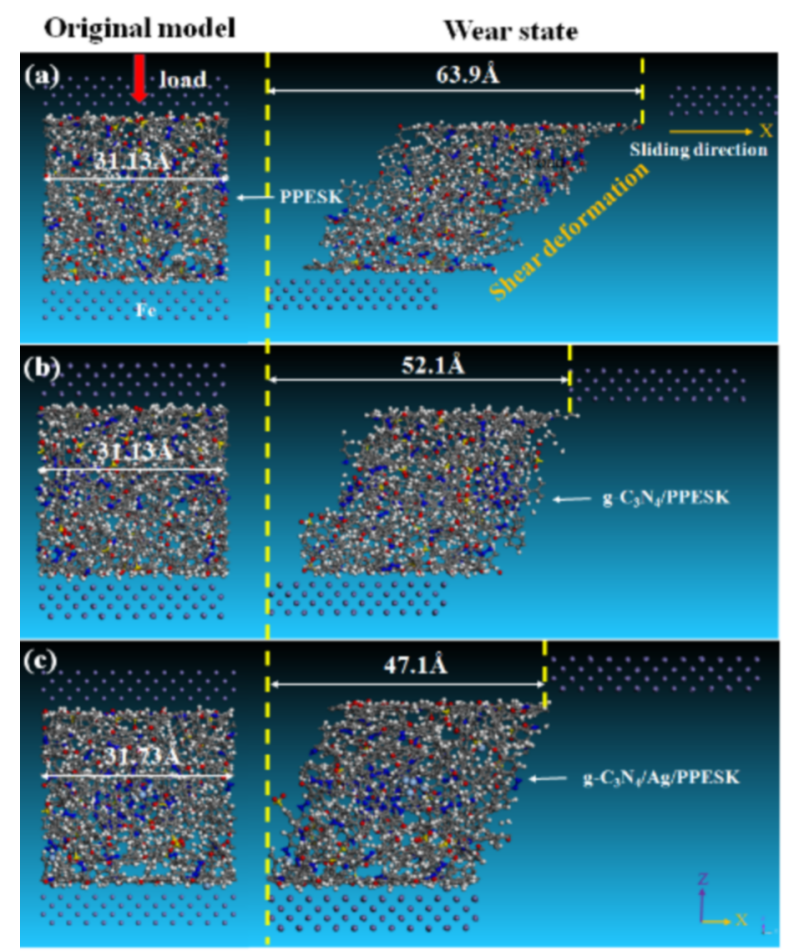

Fig. 7 The snapshots of friction process of PPESK (a), g- $\mathrm{C}_{3} \mathrm{~N}_{4}$-PPESK (b), and g- $\mathrm{C}_{3} \mathrm{~N}_{4} / \mathrm{Ag}$-PPESK (c) sliding against Fe layers at 200 ps. 
with Fe layers, implying the strong interaction between PPESK and Fe atoms under the effect of applied load and shear stress (Fig. 8). For the g- $\mathrm{C}_{3} \mathrm{~N}_{4}-\mathrm{PPESK}$ composite, partial PPESK molecules are absorbed around g- $\mathrm{C}_{3} \mathrm{~N}_{4}$ nanosheets, which results in decreasing the interaction energy with $\mathrm{Fe}$ atomic layers. Moreover, under the synergistic effect of $\mathrm{g}-\mathrm{C}_{3} \mathrm{~N}_{4}$ and $\mathrm{Ag}$ nanoparticles, the interaction potential energy of PPESK composite continuously decreases to 2,183.2 $\mathrm{kcal} / \mathrm{mol}$. It indicates that more PPESK molecules have movement cons-trained due to the strong adsorption of $\mathrm{g}-\mathrm{C}_{3} \mathrm{~N}_{4} / \mathrm{Ag}$. This is the main reason why the $\mathrm{g}-\mathrm{C}_{3} \mathrm{~N}_{4} / \mathrm{Ag}-\mathrm{PPESK}$ composite film has the lowest friction coefficient (i.e., the weakest interaction with $\mathrm{Fe}$ ) and minimum shear deformation under the same condition. In addition, friction characteristics of different materials can be evaluated by the friction heat. Generally, materials with high friction coefficients produce more friction heat on the sliding interface. Hence, more temperature increase is obtained accordingly. In order to further verify the friction-reducing effect of the $\mathrm{g}-\mathrm{C}_{3} \mathrm{~N}_{4} / \mathrm{Ag}$ hybrid, numerical simulations are carried out and the temperature variations of PPESK and its composite films are analyzed during the sliding process. Figure 9 illustrates the obtained results in this regard. It is observed that the temperature continuously increases along the sliding time. However, it is found that pure PPESK with the highest friction coefficient has the largest temperature rise compared to the other two PPESK composites. The temperature profile variation of PPESK composites confirms that the $\mathrm{g}^{-} \mathrm{C}_{3} \mathrm{~N}_{4} / \mathrm{Ag}-$ PPESK has low interaction potential energy, and reasonable friction-reducing and anti-wear properties.

Furthermore, friction and wear performance of studied composites ( $0.3 \mathrm{wt} \% \mathrm{~g}-\mathrm{C}_{3} \mathrm{~N}_{4} / \mathrm{Ag}-\mathrm{PPESK}$ ) under different loads and rotating speeds are characterized. Obtained results are presented in Fig. 10. It is observed that the friction coefficient and wear rate

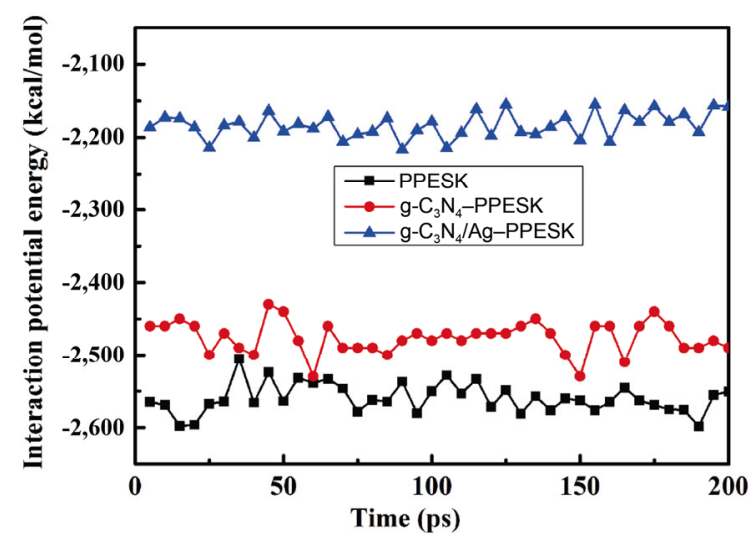

Fig. 8 Interaction potential energy between Fe layers and PPESK and its composite films (minus means adsorption).

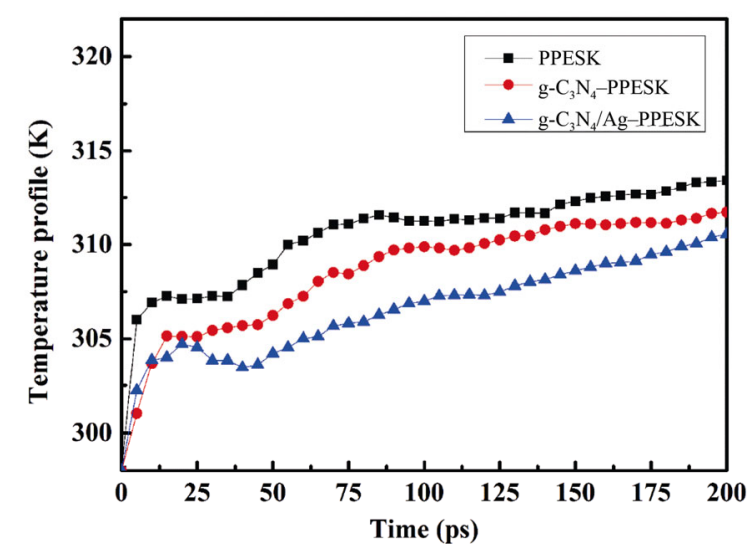

Fig. 9 Variations of temperature on the interface between Fe layers and PPESK and its composite films
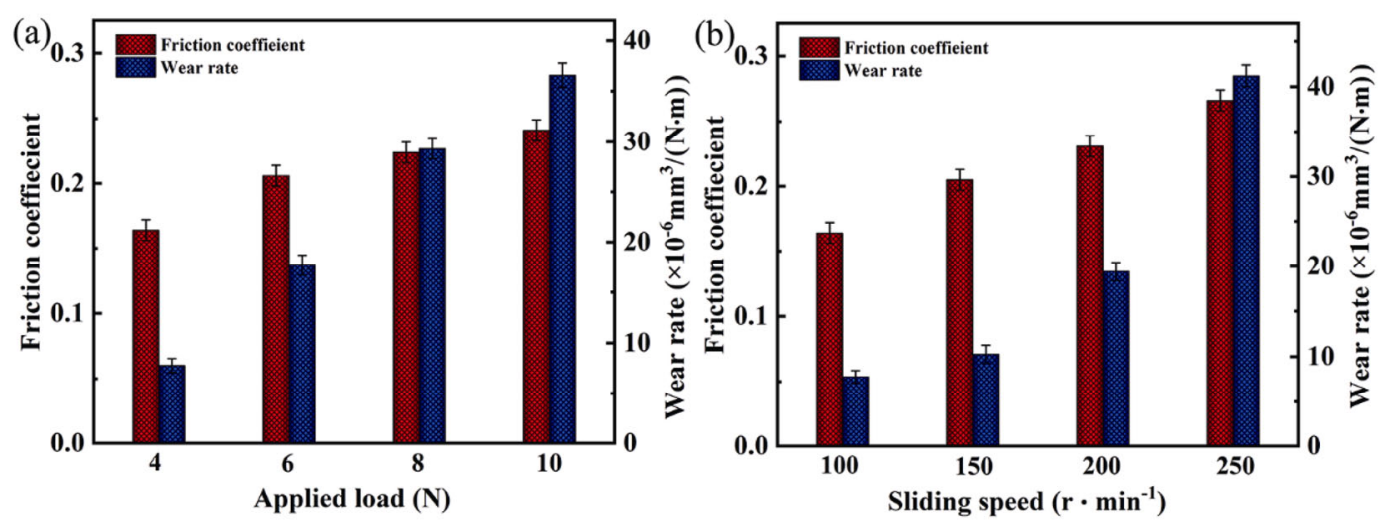

Fig. 10 Friction coefficient and wear rate of PPESK composite film with $0.3 \mathrm{wt} \% \mathrm{~g}-\mathrm{C}_{3} \mathrm{~N}_{4} / \mathrm{Ag}$ hybrid sliding against $440 \mathrm{C}$ stainless ball under different loads (a) and rotating speeds (b). 
of the composite film increase as the applied load and rotating speed increase. It is found that for heavy loads, the contact surface between friction pairs increases [43], so that asperities on the surface of the counterpart penetrate the PPESK composite film much deeper. Accordingly, the PPESK composite film has high serious friction and wear. Moreover, during the friction and wear process, friction heat is generated on the sliding surface and harsh sliding conditions increase the friction heat, making the surface of the composite film have severe plastic deformation and softening, and further being picked-up and worn off. This phenomenon can be explained by the analysis of the worn surface of PPESK composite film in Fig. 13. Nevertheless, the friction coefficient and wear rate of $0.3 \mathrm{wt} \% \mathrm{~g}-\mathrm{C}_{3} \mathrm{~N}_{4} / \mathrm{Ag}$ reinforced PPESK composite film under the load of $10 \mathrm{~N}$ and rotating speed of $250 \mathrm{rpm}$ are much lower than those of pure PPESK under low load or rotating speed. This may be attributed to the synergism between $\mathrm{g}-\mathrm{C}_{3} \mathrm{~N}_{4}$ and mono-dispersed $\mathrm{Ag}$ nanoparticles as well as good interfacial compatibility between $\mathrm{g}-\mathrm{C}_{3} \mathrm{~N}_{4} / \mathrm{Ag}$ hybrid and the polymer matrix. It is concluded that by the incorporation of $\mathrm{g}^{-} \mathrm{C}_{3} \mathrm{~N}_{4} / \mathrm{Ag}$ hybrid, the tribological properties of PPESK can be enhanced significantly, and make it an appropriate choice for operating at high loads and rotating speeds.

\subsection{Analysis of the worn surface}

To further illustrate the friction and wear mechanism of PPESK and its composite films, the worn surface morphologies of pure PPESK, g- $\mathrm{C}_{3} \mathrm{~N}_{4}$-PPESK, and g- $\mathrm{C}_{3} \mathrm{~N}_{4} / \mathrm{Ag}-\mathrm{PPESK}$ are studied by SEM and results are shown in Fig. 11. It is observed that the width of the wear track decreases from the top to the bottom, demonstrating that the addition of $g-\mathrm{C}_{3} \mathrm{~N}_{4}$ and g- $\mathrm{C}_{3} \mathrm{~N}_{4} /$ $\mathrm{Ag}$ significantly improves the wear resistance of the PPESK matrix. This is especially more pronounced for the $\mathrm{g}-\mathrm{C}_{3} \mathrm{~N}_{4} / \mathrm{Ag}$ hybrid. Meanwhile, it is found that the worn surface of PPESK has the widest wear track, and many obvious deep and wide furrows as well as debris and micro-cracks are observed in this regard. It indicates that PPESK suffers from serious fatigue and abrasive wear during the friction and wear process. This finding is consistent with the highest friction coefficient and wear rate of pure PPESK. However, wear tracks in $\mathrm{g}-\mathrm{C}_{3} \mathrm{~N}_{4}-\mathrm{PPESK}$ and g- $\mathrm{C}_{3} \mathrm{~N}_{4} / \mathrm{Ag}-$ PPESK composite films are much shallower and narrower, which may be attributed to the lubricating effect of g-C3N4 and Ag nanoparticles. Furthermore, the debris is scarcely found on the worn surface of g- $\mathrm{C}_{3} \mathrm{~N}_{4} / \mathrm{Ag}-\mathrm{PPESK}$ composite film, and the grooves are much less and shallower (Fig. 11(c)). This is also agreement with the excellent tribological properties of
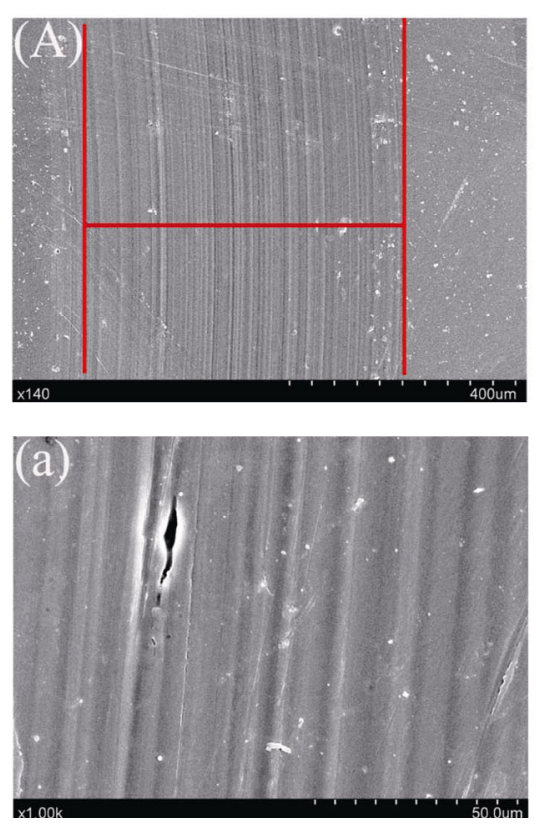
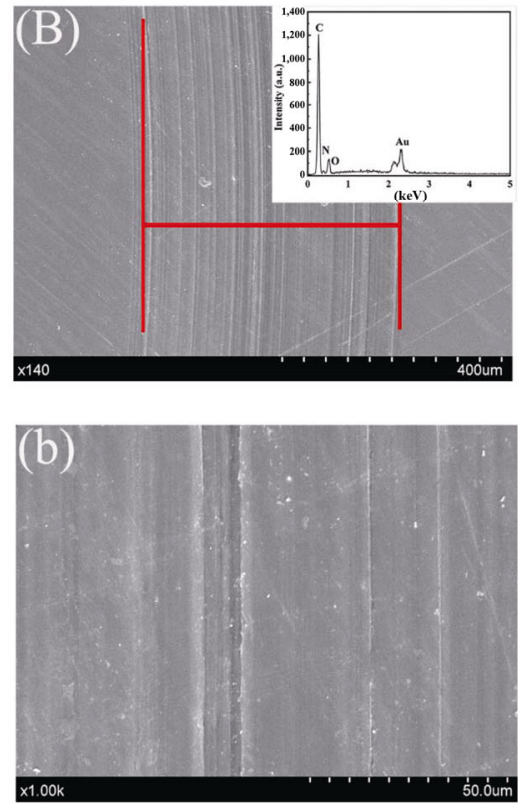
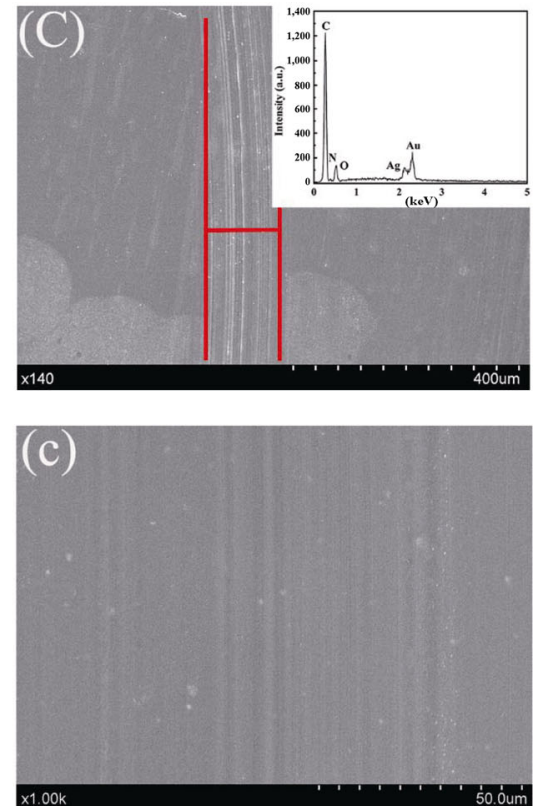

Fig. 11 SEM images and EDS of worn surface of PPESK and its composite films sliding against 440C stainless ball under $4 \mathrm{~N}$, 100 rpm: PPESK (A, a), g- $\mathrm{C}_{3} \mathrm{~N}_{4}-\operatorname{PPESK}(\mathrm{B}, \mathrm{b})$, and g- $\mathrm{C}_{3} \mathrm{~N}_{4} / \mathrm{Ag}-\operatorname{PPESK}(\mathrm{C}, \mathrm{c})$. 
g- $\mathrm{C}_{3} \mathrm{~N}_{4} / \mathrm{Ag}$-PPESK. This can be physically interpreted as the following: the surface of $\mathrm{g}-\mathrm{C}_{3} \mathrm{~N}_{4}$ nanosheets contains a large number of active functional groups, making the PPESK matrix closely bonded with the filler. Accordingly, the shear deformation further decreases, avoiding the removal of the filler and matrix because of the friction. Meanwhile, the monodispersed Ag nanoparticles can carry a part of applied stresses on the surface of the composite film
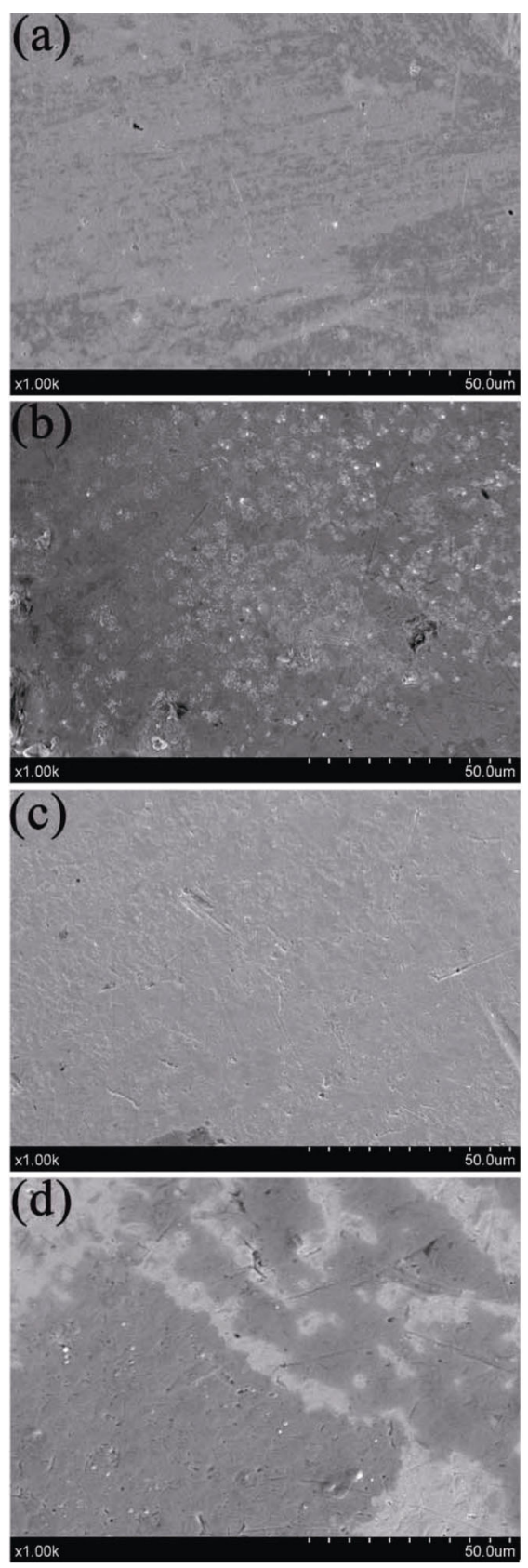

to inhibit the wear of PPESK matrix. Furthermore, the EDS analysis demonstrates the existence of $\mathrm{Ag}$ element on the worn surface. This is because the g- $\mathrm{C}_{3} \mathrm{~N}_{4} / \mathrm{Ag}$ hybrid is gradually exposed on the sliding surface with the proceeding of friction and wear. Ag nanoparticles can play a "micro-roller" effect to reduce the contact area between the friction pair and composite film to decrease the friction.

In addition, Fig. 12 shows the SEM images and
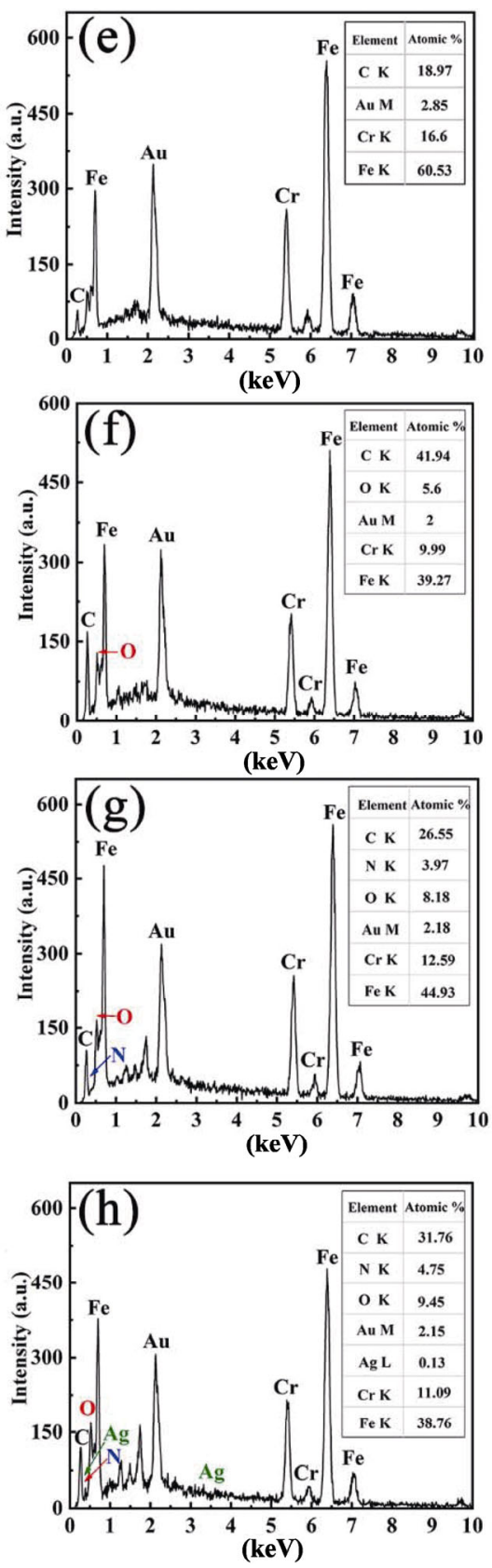

Fig. 12 SEM images and EDS of 440C stainless ball surface before (a, e) and after sliding against PPESK (b, f), g- $\mathrm{C}_{3} \mathrm{~N}_{4}-$ $\operatorname{PPESK}(\mathrm{c}, \mathrm{g})$, and $\mathrm{g}-\mathrm{C}_{3} \mathrm{~N}_{4} / \mathrm{Ag}-\operatorname{PPESK}(\mathrm{d}, \mathrm{h})$ under $4 \mathrm{~N}, 100 \mathrm{rpm}$. 
EDS analysis of $440 \mathrm{C}$ stainless ball before and after friction and wear tests. It is observed that the ball surface becomes much rougher after sliding against PPESK (Fig. 12(a)), coinciding with the worn surface of pure PPESK with deep and wide grooves. Moreover, Figs. 12(c) and 12(g) show that the ball surface is much smoother and has $\mathrm{N}$ element, indicating the existence of $\mathrm{g}-\mathrm{C}_{3} \mathrm{~N}_{4}$. Furthermore, Fig. 12(d) indicates that there are clearly deep gray zones on the stainless ball surface, which might be caused by the formation of the transfer film. Existence of $\mathrm{C}, \mathrm{N}$, and $\mathrm{Ag}$ elements on the counterpart surface confirms this issue. The transfer film containing $\mathrm{g}-\mathrm{C}_{3} \mathrm{~N}_{4} / \mathrm{Ag}$ hybrid can not only decrease the direct contact between the PPESK composite film and the counterpart but also plays an important role in the self-lubricating, finally endowing the composite film with excellent tribological properties.

Figure 13 shows the SEM images of the worn surface of the PPESK composite film containing $0.3 \mathrm{wt} \%$ g- $\mathrm{C}_{3} \mathrm{~N}_{4} / \mathrm{Ag}$ sliding against $440 \mathrm{C}$ stainless ball under a heavy load and high rotating speed. Figs. 13(A, a) show that holes of different sizes appear on the worn surface under the load of $10 \mathrm{~N}$. This is because the contact area between the composite film and coun- terpart is large, and much friction heat produced by a heavier applied load softens the material and creates holes on the surface, which will be further expanded under the action of cyclic forces [44]. Furthermore, when the rotating speed is high, a large amount of friction heat cannot be effectively expelled in time under the condition of dry sliding. Therefore, the asperities on the counterpart pair simply penetrate the surface of PPESK composite film, thereby producing serious wear. Accordingly, many deep furrows and plastic deformation zones are found in Fig. 13(B, b).

\section{Conclusions}

In the present study, a novel hybrid of mono-dispersed Ag nanoparticles decorating $\mathrm{g}-\mathrm{C}_{3} \mathrm{~N}_{4}$ nanosheets is fabricated via a facile and efficient reduction method. Experiments show that the proposed hybrid greatly improves the tribological performance of PPESK. It is found that when the content of $\mathrm{g}-\mathrm{C}_{3} \mathrm{~N}_{4} / \mathrm{Ag}$ hybrid is $0.3 \mathrm{wt} \%$, the friction coefficient and wear rate of PPESK compared with pure PPESK decrease by $68.9 \%$ and $97.1 \%$, respectively. This is mainly attributed to the synergistic self-lubricating effect
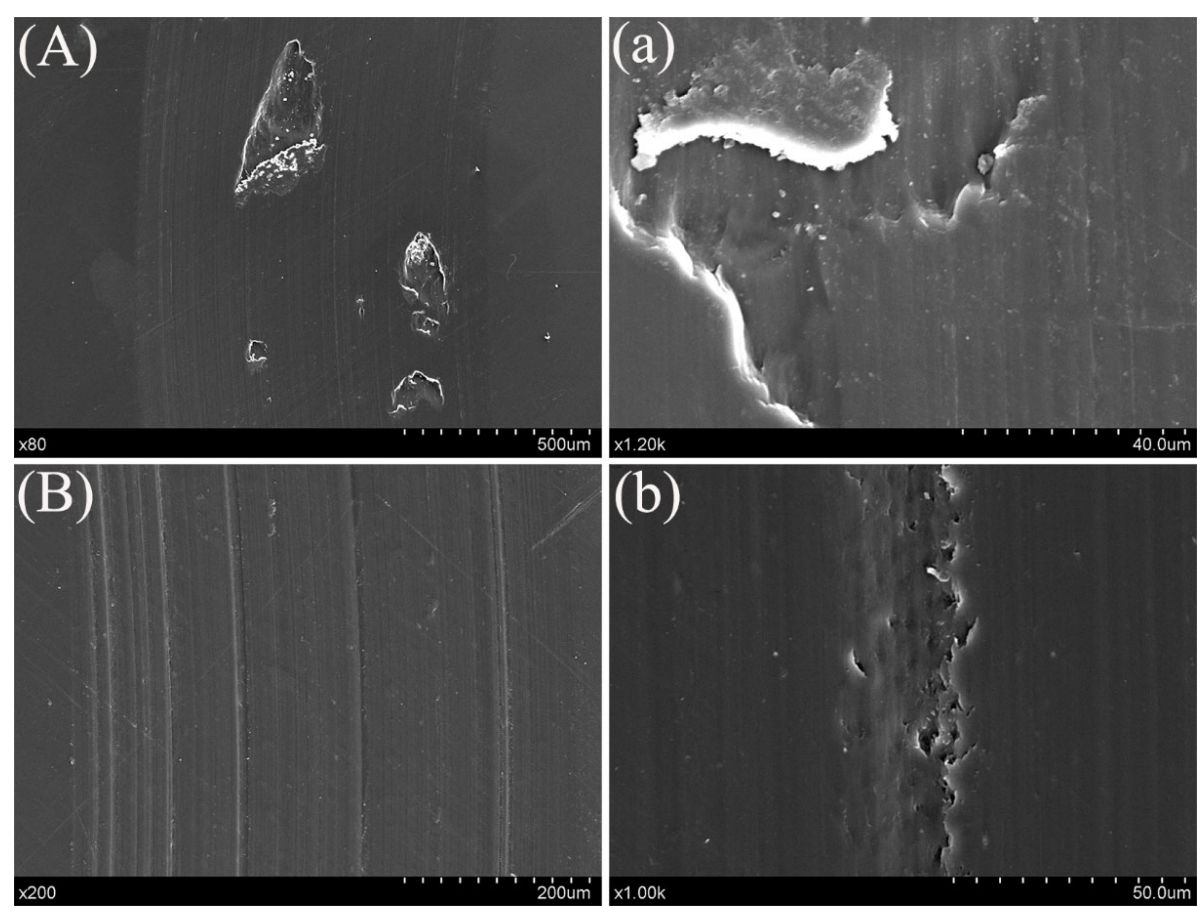

Fig. 13 SEM images of PPESK composite film with $0.3 \mathrm{wt} \% \mathrm{~g}-\mathrm{C}_{3} \mathrm{~N}_{4} / \mathrm{Ag}$ hybrid sliding against $440 \mathrm{C}$ stainless ball under $10 \mathrm{~N}$, $100 \mathrm{rpm}(\mathrm{A}, \mathrm{a})$, and $4 \mathrm{~N}, 250 \mathrm{rpm}(\mathrm{B}, \mathrm{b})$. (A) and (B) are low magnification SEM images, while (a) and (b) are the corresponding high magnification SEM images. 
of mono-dispersed Ag nanoparticles and $\mathrm{g}-\mathrm{C}_{3} \mathrm{~N}_{4}$ nanosheets, and their good interfacial compatibility with the PPESK matrix. Furthermore, the theoretical simulation further confirms that the proposed g- $\mathrm{C}_{3} \mathrm{~N}_{4} / \mathrm{Ag}$ hybrid can effectively decrease the shear deformation of the PPESK composite film and the interaction potential energy between the composite film and counterpart. Moreover, it is found that the proposed hybrid reinforced PPESK composite film has excellent friction-reducing and wear-resistant performance, even under heavy loads and high rotating speeds. Based on the obtained results, it is concluded that the proposed $\mathrm{g}-\mathrm{C}_{3} \mathrm{~N}_{4} / \mathrm{Ag}$ hybrid is an excellent lubricating additive for polymer composites, and can provide novel guidance for designing highperformance polymer self-lubricating composites.

\section{Acknowledgements}

This work was financially supported by the Project of Jiangsu Provincial Six Talent Peak (No. XCL-214), Foundation of State Key Laboratory of Solid lubrication (No. LSL-1709), and Senior Intellectuals Fund of Jiangsu University (No. 13JDG099).

Electronic Supplementary Material: Supplementary material is available in the online version of this article at https://doi.org/10.1007/s40544-021-0487-3.

Open Access This article is licensed under a Creative Commons Attribution 4.0 International License, which permits use, sharing, adaptation, distribution and reproduction in any medium or format, as long as you give appropriate credit to the original author(s) and the source, provide a link to the Creative Commons licence, and indicate if changes were made.

The images or other third party material in this article are included in the article's Creative Commons licence, unless indicated otherwise in a credit line to the material. If material is not included in the article's Creative Commons licence and your intended use is not permitted by statutory regulation or exceeds the permitted use, you will need to obtain permission directly from the copyright holder.

To view a copy of this licence, visit http://creativecommons.org/licenses/by/4.0/.

\section{References}

[1] Holmberg K, Erdemir A. Influence of tribology on global energy consumption, costs and emissions. Friction 5(3): 263-284 (2017)

[2] Luo J B, Zhou X. Superlubricitive engineering-Future industry nearly getting rid of wear and frictional energy consumption. Friction 8(4): 643-665 (2020)

[3] Shen M X, Li B, Zhang Z N, Zhao L Z, Xiong G Y. Abrasive wear behavior of PTFE for seal applications under abrasive-atmosphere sliding condition. Friction 8(4): 755-767 (2020)

[4] Chen B B, Li X, Jia Y H, Li X F, Yang J, Yan F Y, Li C S. $\mathrm{MoS}_{2}$ nanosheets-decorated carbon fiber hybrid for improving the friction and wear properties of polyimide composite. Compos Part A Appl Sci Manuf 109: 232-238 (2018)

[5] Zhu J J, Ma L, Dwyer-Joyce R. Friction and wear behaviours of self-lubricating peek composites for articulating pin joints. Tribol Int 149: 105741 (2020)

[6] Chen B B, Jia Y H, Zhang M J, Liang H Y, Li X, Yang J, Yan F Y, Li C S. Tribological properties of epoxy lubricating composite coatings reinforced with core-shell structure of $\mathrm{CNF} / \mathrm{MoS}_{2}$ hybrid. Compos Part A Appl Sci Manuf 122: 85-95 (2019)

[7] Avilés M D, Jiménez A E, Saurín N, Carrión F J, Bermúdez M D. Tribological characterization of epoxy coatings modified with ionic liquids and graphene. Tribol Int 149: 105516 (2020)

[8] Zhang X Y, Chen P, Han D B, Yu Q, Ding Z F, Zhu X L. Effect of thermoplastic coating on interfacial adhesion of oxygen-plasma-pretreated PBO/PPESK composites. Appl Surf Sci 266: 110-117 (2013)

[9] Cao F X, Jiang P F, Wang J Z, Yan F Y. Tribological properties of poly(phthalazione ether sulfone ketone) composites reinforced with glass fabric modified by graphene oxide depositing. Surf Interf Anal 50(6): 667-673 (2018)

[10] Zhang M J, Chen B B, Dong Z, Wang S, Li X, Jia Y H, Yan F Y. Enhancement on the tribological properties of poly(phthalazinone ether sulfone ketone) by carbon nanotube-supported graphitic carbon nitride hybrid. Polym Compos 41(9): 3768-3777 (2020)

[11] Min C Y, Liu D D, Qian J M, He Z B, Jia W, Song H J, Guo L. High mechanical and tribological performance polyimide nanocomposites using amine-functionalized graphene nanosheets. Tribol Int 131: 1-10 (2019)

[12] Gong K L, Lou W J, Zhao G Q, Wu X H, Wang X B. Investigation on tribological behaviors of $\mathrm{MoS}_{2}$ and $\mathrm{WS}_{2}$ quantum dots as lubricant additives in ionic liquids under severe conditions. Friction 8(4): 674-683 (2020)

[13] Xu Y K, Guo Y X, Li G T, Zhang L G, Zhao F Y, Guo X P, Dmitriev A I, Zhang G. Role of hydrolysable nanoparticles 
on tribological performance of PPS-steel sliding pair lubricated with sea water. Tribol Int 127: 147-156 (2018)

[14] Chen Z Y, Yan H X, Guo L L, Feng Y B, Li L, Feng W X, Yang P F, Liu B, Liu T Y F, Yuan J S. Investigation of mechanical and frictional performance for bismaleimide composites reinforced by hyperbranched polysiloxanecyclophosphazene functionalized $\mathrm{rGO} / \mathrm{MoS}_{2}$. J Alloys Compd 823: 153837 (2020)

[15] Yu J J, Zhao W J, Wu Y H, Wang D L, Feng R T. Tribological properties of epoxy composite coatings reinforced with functionalized $\mathrm{C}-\mathrm{BN}$ and $\mathrm{H}-\mathrm{BN}$ nanofillers. Appl Surf Sci 434: 1311-1320 (2018)

[16] Yuan H, Liu X H, Ma L M, Yang Z G, Wang H G, Wang J Q, Yang S R. Application of two-dimensional $\mathrm{MoS}_{2}$ nanosheets in the property improvement of polyimide matrix: Mechanical and thermal aspects. Compos Part $A$ Appl Sci Manuf 95: 220-228 (2017)

[17] Ye X Y, Liu X H, Yang Z G, Wang Z F, Wang H G, Wang J Q, Yang S R. Tribological properties of fluorinated graphene reinforced polyimide composite coatings under different lubricated conditions. Compos Part $A$ Appl Sci Manuf 81: 282-288 (2016)

[18] Chen B B, Zhang M J, Li X, Dong Z, Jia Y H, Li C S. Tribological properties of epoxy-based self-lubricating composite coating enhanced by 2D/2D h-BN/MoS hybrid. Prog Org Coat 147: 105767 (2020)

[19] Hong Y Z, Shi J Y, Shi W D, Fang Z Y, Chen R J, Huang Y Y. A facile and scalable route for synthesizing ultrathin carbon nitride nanosheets with efficient solar hydrogen evolution. Carbon 136: 160-167 (2018)

[20] Zhao H Z, Chen X L, Jia C C, Zhou T, Qu X H, Jian J K, $\mathrm{Xu}$ Y P, Zhou T. A facile mechanochemical way to prepare $\mathrm{g}_{-} \mathrm{C}_{3} \mathrm{~N}_{4}$. Mater Sci Eng B 122(2): 90-93 (2005)

[21] Zhang L G, Qi H M, Li G T, Wang D A, Wang T M, Wang Q H, Zhang G. Significantly enhanced wear resistance of PEEK by simply filling with modified graphitic carbon nitride. Mater Des 129: 192-200 (2017)

[22] Zhu L, You L J, Shi Z X, Song H J, Li S J. An investigation on the graphitic carbon nitride reinforced polyimide composite and evaluation of its tribological properties. J Appl Polym Sci 134(41): 45403 (2017)

[23] Chou R, Battez A H, Cabello J J, Viesca J L, Osorio A, Sagastume A. Tribological behavior of polyalphaolefin with the addition of nickel nanoparticles. Tribol Int 43(12): 2327-2332 (2010)

[24] Tarasov S, Kolubaev A, Belyaev S, Lerner M, Tepper F. Study of friction reduction by nanocopper additives to motor oil. Wear 252(1-2): 63-69 (2002)

[25] Jia X H, Huang J, Li Y, Yang J, Song H J. Monodisperse $\mathrm{Cu}$ nanoparticles@ $\mathrm{MoS}_{2}$ nanosheets as a lubricant additive for improved tribological properties. Appl Surf Sci 494: 430-439 (2019)
[26] Jia Z F, Chen T D, Wang J, Ni J J, Li H Y, Shao X. Synthesis, characterization and tribological properties of $\mathrm{Cu} /$ reduced graphene oxide composites. Tribol Int $\mathbf{8 8}$ : 17-24 (2015)

[27] Song H J, Wang Z Q, Yang J, Jia X H, Zhang Z Z. Facile synthesis of copper/polydopamine functionalized graphene oxide nanocomposites with enhanced tribological performance. Chem Eng J 324: 51-62 (2017)

[28] Kumara C, Luo H M, Leonard D N, Meyer H M, Qu J. Organic-modified silver nanoparticles as lubricant additives. ACS Appl Mater Interfaces 9(42): 37227 37237 (2017)

[29] Wang L, Gong P W, Li W, Luo T, Cao B Q. Monodispersed Ag/Graphene nanocomposite as lubricant additive to reduce friction and wear. Tribol Int 146: 106228 (2020)

[30] Sun H. COMPASS: An ab initio force-field optimized for condensed-phase applications-overview with details on alkane and benzene compounds. J Phys Chem B 102(38): 7338-7346 (1998)

[31] Huang J, Yang W L, Zhu J J, Fu L C, Li D Y, Zhou L P. Silver nanoparticles decorated 3D reduced graphene oxides as hybrid filler for enhancing thermal conductivity of polystyrene composites. Compos Part A Appl Sci Manuf 123: 79-85 (2019)

[32] Wang C F, Zhao M, Li J, Yu J L, Sun S F, Ge S S, Guo X K, Xie F, Jiang B, Wujcik E K, et al. Silver nanoparticles/graphene oxide decorated carbon fiber synergistic reinforcement in epoxy-based composites. Polymer 131: 263-271 (2017)

[33] Chen H, Yang F Y, Hu R D, Zhang M Z, Ren B P, Gong X, Ma J, Jiang B B, Chen Q, Zheng J. A comparative study of the mechanical properties of hybrid doublenetwork hydrogels in swollen and as-prepared states. $J$ Mater Chem B 4(35): 5814-5824 (2016)

[34] Song B, Wang T T, Sun H G, Liu H, Mai X M, Wang X J, Wang L, Wang N, Huang Y D, Guo Z H. Graphitic carbon nitride $\left(\mathrm{g}-\mathrm{C}_{3} \mathrm{~N}_{4}\right)$ interfacially strengthened carbon fiber epoxy composites. Compos Sci Technol 167: 515-521 (2018)

[35] Niu P, Zhang L L, Liu G, Cheng H M. Graphene-like carbon nitride nanosheets for improved photocatalytic activities. Adv Funct Mater 22(22): 4763-4770 (2012)

[36] Wu L F, Zhang Z Z, Yang M M, Yuan J Y, Li P L, Guo F, Men X H. One-step synthesis of $g-\mathrm{C}_{3} \mathrm{~N}_{4}$ nanosheets to improve tribological properties of phenolic coating. Tribol Int 132: 221-227 (2019)

[37] Ren L L, Li Q, Lu J B, Zeng X L, Sun R, Wu J B, Xu J B, Wong C P. Enhanced thermal conductivity for Ag-deposited alumina sphere/epoxy resin composites through manipulating interfacial thermal resistance. Compos Part A Appl Sci Manuf 107: 561-569 (2018) 
[38] Hao M Z, Tang M M, Wang W C, Tian M, Zhang L Q, Lu Y L. Silver-nanoparticle-decorated multiwalled carbon nanotubes prepared by poly(dopamine) functionalization and ultraviolet irradiation. Compos Part B Eng 95: 395-403 (2016)

[39] Zhang B, Wang T H, Zhang S H, Qiu J S, Jian X G. Preparation and characterization of carbon membranes made from poly(phthalazinone ether sulfone ketone). Carbon 44(13): 2764-2769 (2006)

[40] Gaddam S K, Pothu R, Boddula R. Graphitic carbon nitride $\left(\mathrm{g}-\mathrm{C}_{3} \mathrm{~N}_{4}\right)$ reinforced polymer nanocomposite systems-A review. Polym Compos 41(2): 430-442 (2020)

[41] Tang G B, Su F H, Xu X, Chu P K. 2D black phosphorus dotted with silver nanoparticles: An excellent lubricant

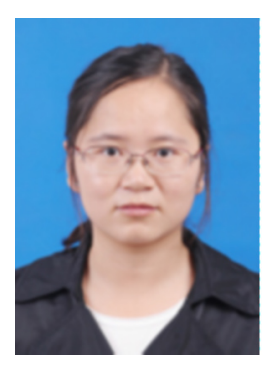

Beibei CHEN. She is currently an associate researcher at Jiangsu University. She received her B.S. degree from Henan University in 2008 and Ph.D. degree from additive for tribological applications. Chem Eng $J$ 392: 123631 (2020)

[42] Yang J, Zhang H T, Chen B B, Tang H, Li C S, Zhang Z Z. Fabrication of the $\mathrm{g}-\mathrm{C}_{3} \mathrm{~N}_{4} / \mathrm{Cu}$ nanocomposite and its potential for lubrication applications. RSC $A d v$ 5(79): 64254-64260 (2015)

[43] Chen B B, Li X F, Li X, Yang J, Peng W X, Dong J Z, Li C S, Song H J. Facile fabrication of hierarchical carbon fiber- $\mathrm{MoS}_{2}$ ultrathin nanosheets and its tribological properties. RSC Adv 6(65): 60446-60453 (2016)

[44] Chen B B, Li X F, Li X, Jia Y H, Yang J, Yang G B, Li C $\mathrm{S}$. Friction and wear properties of polyimide-based composites with a multiscale carbon fiber-carbon nanotube hybrid. Tribol Lett 65(3): 111 (2017)

Lanzhou Institute of Chemical Physics, Chinese Academy of Sciences in 2013. Her current research interests cover the tribology of polymer nanocomposites and interface/surface analysis. 